\title{
High-Frequency Hippocampal Oscillations Activated by Optogenetic Stimulation of Transplanted Human ESC-Derived Neurons
}

\author{
Juan C. Piña-Crespo, ${ }^{1 \star}$ Maria Talantova, ${ }^{1 *}$ Eun-Gyung Cho,,${ }^{1 *}$ Walid Soussou, ${ }^{1}$ Nima Dolatabadi, ${ }^{1}$ Scott D. Ryan, ${ }^{1}$ \\ Rajesh Ambasudhan, ${ }^{1}$ Scott McKercher, ${ }^{1}$ Karl Deisseroth, ${ }^{2}$ and Stuart A. Lipton ${ }^{1}$ \\ ${ }^{1}$ Del E. Webb Center for Neuroscience, Aging, and Stem Cell Research, Sanford-Burnham Medical Research Institute, La Jolla, California 92037, and \\ ${ }^{2}$ Department of Psychiatry and Behavioral Sciences, Stanford University, Stanford, California 94305
}

After transplantation, individual stem cell-derived neurons can functionally integrate into the host CNS; however, evidence that neurons derived from transplanted human embryonic stem cells (hESCs) can drive endogenous neuronal network activity in CNS tissue is still lacking. Here, using multielectrode array recordings, we report activation of high-frequency oscillations in the $\beta$ and $\gamma$ ranges (10-100 $\mathrm{Hz}$ ) in the host hippocampal network via targeted optogenetic stimulation of transplanted hESC-derived neurons.

\section{Introduction}

The ability of transplanted stem cell-derived neurons to receive and send functional excitatory and inhibitory inputs is a key indicator of successful functional integration into the CNS (Kim et al., 2002; Benninger et al., 2003; Wernig et al., 2004; Lee et al., 2007; Li et al., 2008; Weick et al., 2010, 2011); however, it remains to be shown that whole populations of transplanted human embryonic stem cell (hESC)-derived neurons can drive the activity of local neural networks in the brain. Since local neural circuits in organotypic hippocampal slices retain the ability to generate synchronized high-frequency oscillations (Fischer et al., 2002), and they can support the maturation and integration of transplanted stem cell-derived neurons (Benninger et al., 2003; Scheffler et al., 2003; Opitz et al., 2007), we used this system to ask whether transplanted hESC-derived neurons can integrate and drive neuronal network activity in the CNS. By combining the high spatial resolution provided by optogenetics [via expression of genetically encoded photosensitive membrane proteins (Zhang et al., 2006) in transplanted hESC-derived neurons] with electrophysiological recording of local neuronal network activity [using multielectrode array (MEA) techniques (Taketani and

\footnotetext{
Received Aug. 3, 2012; accepted Sept. 9, 2012

Author contributions: J.C.P.-C., M.T., E.-G.C., W.S., S.M., and S.A.L. designed research; J.C.P.-C., M.T., E.-G.C., W.S., N.D., S.D.R., S.M., and R.A. performed research; K.D. contributed unpublished reagents/analytic tools; J.C.P.-C., M.T., E.-G.C., W.S., and S.M. analyzed data; J.C.P.-C., M.T., E.-G.C., and S.A.L. wrote the paper.

This work was supported by California Institute for Regenerative Medicine (CIRM) Comprehensive Grant RC100125-1 and NIH Grants P01 HD29587, P01 ES016738, P30 NS076411, R01 EY05477, and R01 EY09024 (to S.A.L.). We thank Traci Fang Newmeyer for excellent technical assistance.

*J.C.P.-C., M.T., and E.-G.C. contributed equally to this work.

Correspondence should be addressed to Stuart A. Lipton or Juan C. Piña-Crespo at the above address. E-mail: slipton@sbmri.org or pina-crespo@sbmri.org.

E.-G. Cho's present address: R\&D Center, Amorepacific Corporation, Yongin-si, Gyeonggi-do, South Korea.

W. Soussou's present address: Quantum Applied Science and Research, San Diego, California.

DOI:10.1523/JNEUROSCI.3735-12.2012

Copyright $\odot 2012$ the authors $\quad 0270-6474 / 12 / 3215837-06 \$ 15.00 / 0$
}

Baudry, 2006)], we were able to elicit high-frequency oscillations in the $\beta / \gamma$ range $(10-100 \mathrm{~Hz})$ in the host hippocampal network. Since light stimulation specifically activated the transplanted hESC-derived neurons, we could show that these new neurons behaved not only as conductors of electrical impulses along a network but could also actively engage local neuronal networks into firing at frequency rates commonly observed during normal processing of neural information in the hippocampus (Traub et al., 1999a).

\section{Materials and Methods}

hESC culture and neural induction. Differentiation of hESCs into neurons was performed using a modification of previously described methods (Elkabetz and Studer, 2008; Li et al., 2008; Cho et al., 2011). Briefly, undifferentiated H9 hESCs were grown on a monolayer of fibroblasts from human foreskin (Hs27, ATCC). Cell culture medium was composed of DMEM/F12, knock-out serum replacement $(20 \%)$, basic fibroblast growth factor $(8 \mathrm{ng} / \mathrm{ml}), \beta$-mercaptoethanol $(0.1$ $\mathrm{mm})$, and nonessential amino acids ( $1 \mathrm{~mm})$. Media changes were performed daily and cells were subcultured on a weekly basis. For neural stem/progenitor cell (NPC) induction, hESCs were incubated for $24 \mathrm{~h}$ in cell culture medium composed of DMEM/F12:Neurobasal (1:1), B27 serum-free supplement (2\%), and N2 serum-free supplement (1\%). They were then mechanically dissociated until small clusters of cells were obtained. These cell clusters were cultured for up to $72 \mathrm{~h}$ in the same medium. For neural expansion, cells were grown for up to $6 \mathrm{~d}$ in cell culture medium composed of DMEM/F12:Neurobasal (1: $1)$, B27 serum-free supplement (1\%), N2 serum-free supplement $(0.5 \%)$, basic fibroblast growth factor $(20 \mathrm{ng} / \mathrm{ml})$, and epidermal growth factor $(20 \mathrm{ng} / \mathrm{ml})$. Cells were then plated on dishes coated with $10 \mu \mathrm{g} / \mathrm{ml}$ laminin and grown for up to $48 \mathrm{~h}$ until they took a rosettelike appearance. These rosette-neural stem cells (R-NSCs) were retrieved using a needle and transferred to a dish where they were cultured for 3-30 d in the same medium.

Immunocytochemistry and immunoblots. Epifluorescence microscopy for immunocytochemical analysis and gel electrophoresis followed by immunoblot analysis were performed as previously described (Li et al., 2008; Cho et al., 2011). Primary antibodies in- 
A
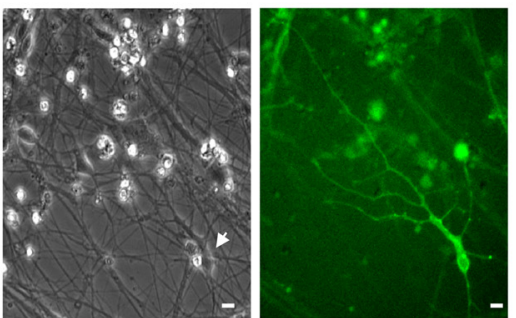

C

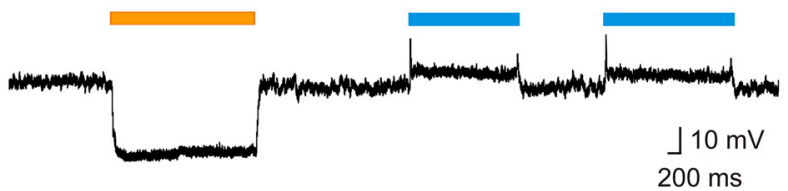

B

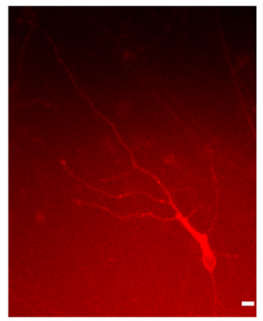

B

$-50 \mathrm{mV}$

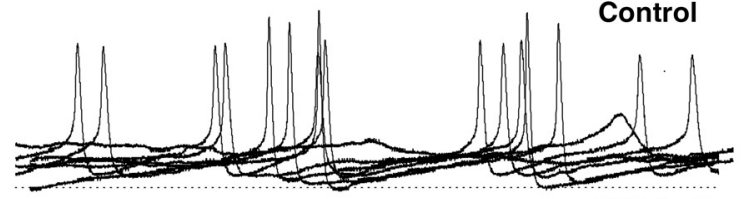

TTX $1 \mu \mathrm{M}$

$-50 \mathrm{mV}$

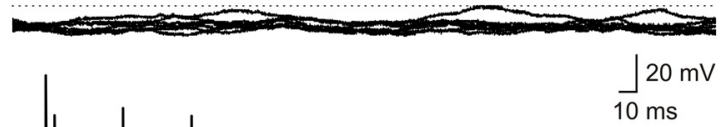

D

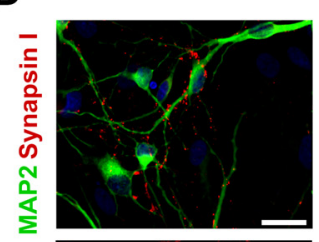

들
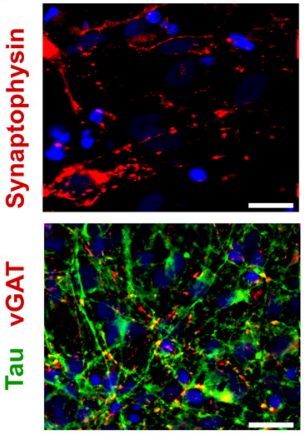
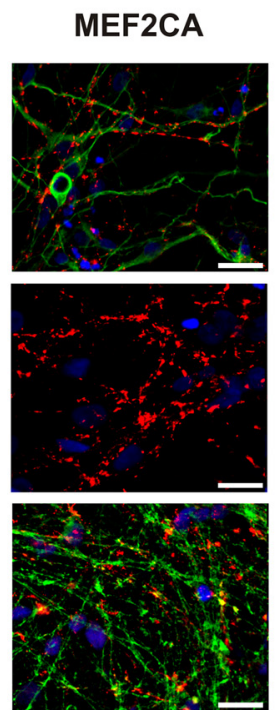

E

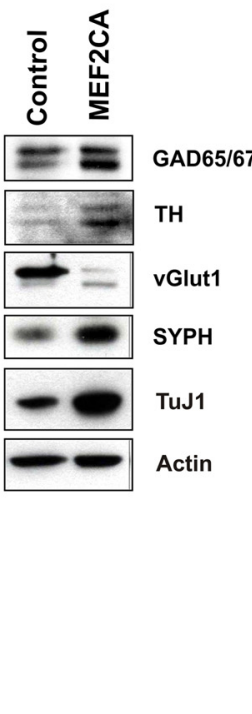

F

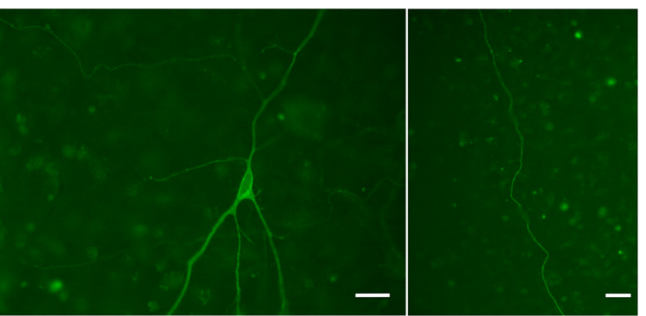

G

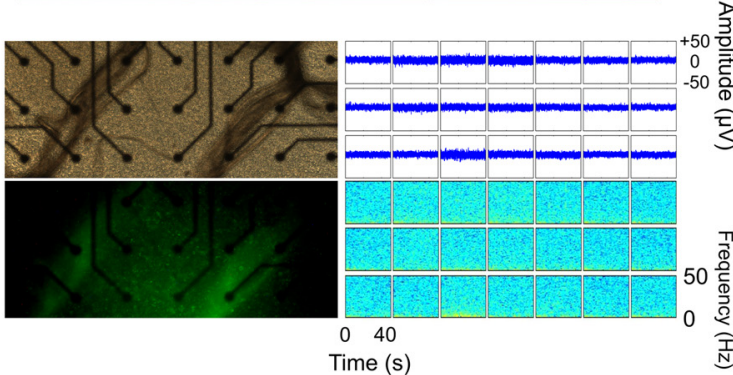

Figure 1. hESC-derived neurons programmed with MEF2CA expressing both ChR2 and NpHR show light-activated whole-cell responses. $A$, Differential interference contrast microscopy and epifluorescent images of hESC-derived neurons in culture that were transduced with lentiviral expression vectors carrying genes encoding light-gated conductances [channelrhodopsin-2 (pSynlChR2-EYFP) and halorhodopsin (pEF1-NpHR-mCherry)]. B, Train of spontaneous action potentials generated by a hESC-derived neuron under current-clamp mode (Iclamp; 3 months in culture). Spontaneous action potentials were sensitive to tetrodotoxin (TTX, $1 \mu \mathrm{M}$ ), a selective sodium channel blocker. C, Current-clamp recording (Iclamp) of light-activated whole-cell responses from hESC-derived neurons in culture 2 weeks posttransduction. Whole-cell recordings were performed using a K-gluconate-based internal solution. Resting membrane potential was $\sim-40 \mathrm{mV}$. To reduce sodium-channel inactivation at this depolarized resting membrane potential, cells were first hyperpolarized by activating NpHR-mediated responses using light at a wavelength of $585 \mathrm{~nm}$ followed by ChR2-mediated depolarization with light at a wavelength of $475 \mathrm{~nm}$. Bottom, ChR2-mediated whole-cell response and action potentials from a cultured neuron. $\boldsymbol{D}$, Typical staining pattern of neurites from MEF2CA-programmed and control vector-infected hESC-derived neurons. Panels show expression pattern of the neuronal proteins MAP2 and tau, and the synaptic markers synapsin I, synaptophysin, and vesicular GABA transporter (VGAT). E, Western blot analysis of neuronal markers from MEF2CA-programmed and control vector-infected hESC-derived neurons. MEF2CA-programmed neurons displayed higher levels of neurotransmitter synthetic enzymes for GABA [glutamic acid decarboxylase (GAD65/67)] and dopamine [tyrosine hydroxylase (TH)], but reduced levels of vesicular glutamate transporter 1 protein (vGlut1). Note the higher levels of the specific neuronal proteins TuJ1 and synaptophysin (SYPH) confirm the enhanced level of neurogenesis produced by MEF2CA. $\boldsymbol{F}$, Representative engrafted hESC-derived neuron in an organotypic hippocampal slice 2 weeks after transplantation. Transplanted hESC-derived neurons developed dendrite-like and axon-like neurites that extended across the slice. Scale bars, $25 \mu \mathrm{m}$. G, Lack of response to photostimulation of a control slice engrafted with MEF2CA-programmed hESC-derived neurons expressing GFP but without optogenetic constructs. Left, Photomicrographs of differential interference contrast and fluorescent images of the slice. Right, MEA traces and spectral analysis show absence of high-frequency oscillations.

cluded the following: $\beta$-tubulin III (TuJ1; mouse, 1:1000, Covance), microtubule-associated protein 2 (MAP2; mouse, 1:1000, Sigma), synaptophysin (rabbit, 1:1000, Dako), tyrosine hydroxylase (mouse, 1:1000, Pel-Freez; rabbit, 1:1000, Millipore Bioscience Research Reagents), glutamate transporter 1 protein (mouse, 1:1000), and glutamic acid decarboxylase (rabbit, 1:500, Abcam). Alexa 488-, 555-, or 647-conjugated goat anti-mouse or anti-rabbit IgGs (1:1000, Invitrogen) were used as secondary antibodies.

Lentiviral infection of R-NSCs and transplantation. Cells at the R-NSC stage were transduced with lentiviral expression vectors. As previously described, to enhance neurogenesis, we expressed a lentivirus containing a constitutively active form of the transcription factor myocyte enhancer factor-2 (MEF2CA) (Li et al., 2008; Cho et al., 2011). Additional lentiviral vectors included pSynapsinI-hChR2-EGFP and pEF1-NpHR-mCherry (Zhang et al., 2006). Once infected, R-NSCs were dissociated and transferred to plates coated with a mixture of $10 \mu \mathrm{g} / \mathrm{ml}$ poly-l-ornithine and 1 $\mu \mathrm{g} / \mathrm{ml}$ laminin. These R-NSCs were grown to become human NPCs (hNPCs) as a monolayer in the medium for neural expansion. At this point, hNPCs were enzymatically dissociated into a single cell suspension using Accutase. For transplantation, hNPCs were washed in $\mathrm{Ca}^{2+}$ / $\mathrm{Mg}^{2+}$-free HBSS and concentrated. Cells were placed onto the CA3 region using a glass micropipette attached to a nanoliter injector (Nanoject, Drummond). Each slice received a single injection of a single-cell suspension containing 50,000-100,000 cells. Slices were placed back in a 
A

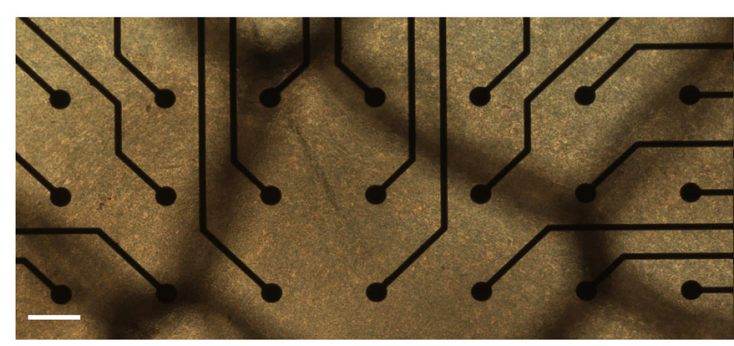

B

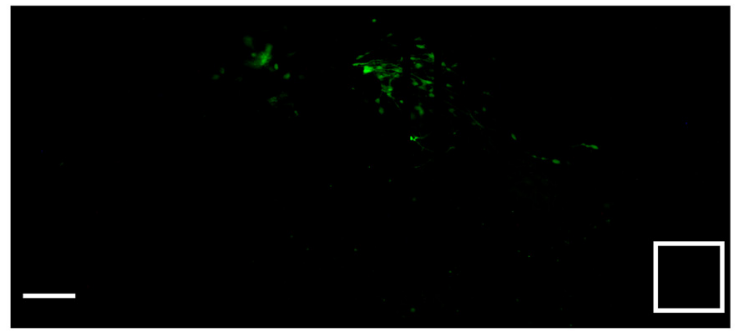

C

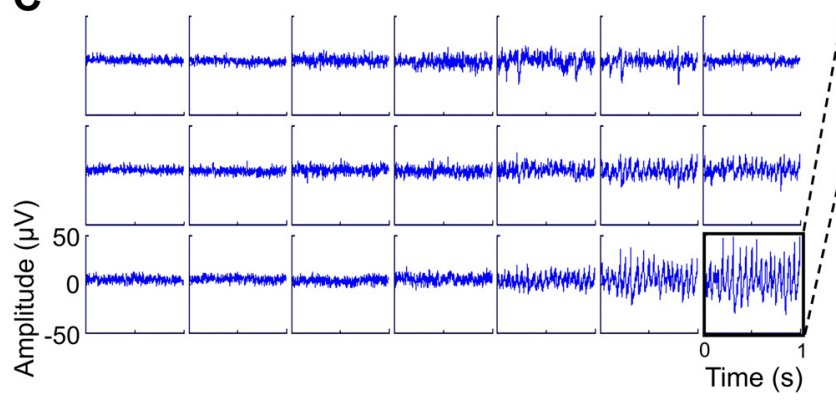

D

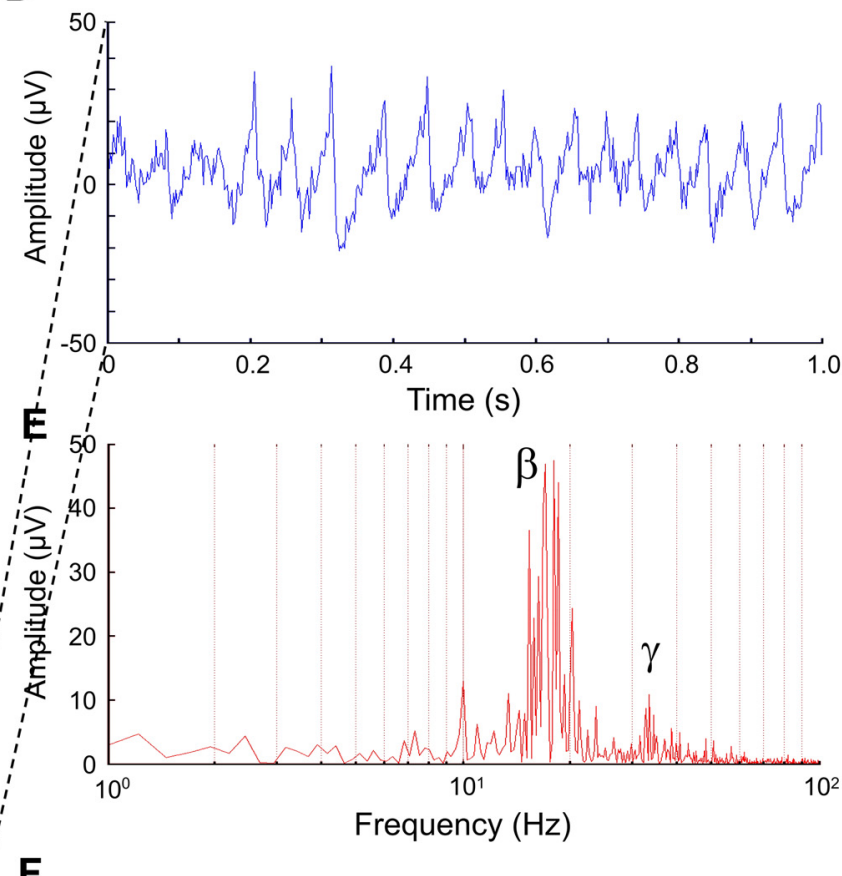

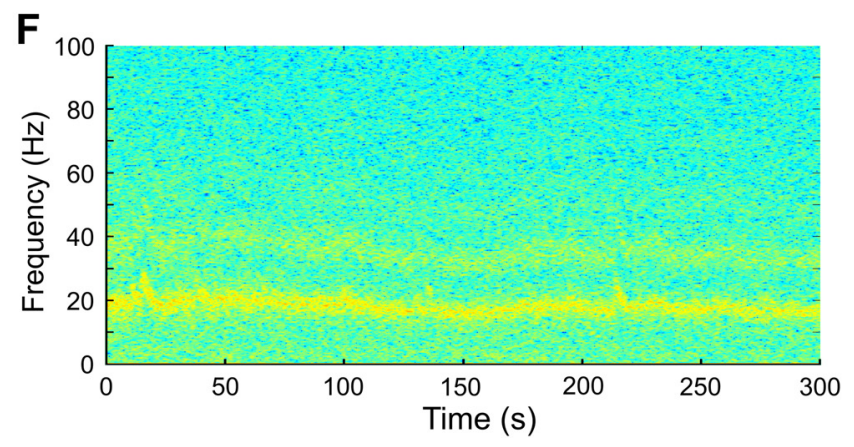

Figure 2. Optogenetic activation of engrafted hESC neurons elicits high-frequency oscillations in the $\beta$ and $\gamma$ ranges $(10-100 \mathrm{~Hz})$ in the hippocampus in vitro. $A$, Representative differential interference contrast image showing organotypic hippocampal slice containing engrafted hESC-derived neurons $17 \mathrm{~d}$ postseeding. The surface of the slice containing the cells was placed in direct contact with planar electrodes of an MEA recording chamber. $\boldsymbol{B}$, Fluorescent image of the same slice showing engrafted hESC-derived neurons. The white square shows a region of the slice devoid of engrafted hESC-derived neurons from which extracellular activity was continuously recorded. Scale bar, $100 \mu \mathrm{m}$. C, Traces show characteristic extracellular local field potentials after stimulation with blue light (wavelength, $475 \mathrm{~nm}$ ) to stimulate ChR2. Neuronal network activity was recorded before, during, and after light stimulation. Extracellular local field potentials were recorded in artificial CSF at $32^{\circ} \mathrm{C} . \boldsymbol{D}$, Same trace as in $\mathrm{C}$ on an expanded time scale showing characteristic extracellular activity observed in the same region of the slice devoid of engrafted $\mathrm{hESC}-$ derived neurons. $\boldsymbol{E}$, Fast Fourier transform analysis of the entire trace $(300 \mathrm{~s})$ reveals a main peak frequency at $18 \mathrm{~Hz}$ and a second peak at $\sim 33 \mathrm{~Hz}$. $\boldsymbol{F}$, Spectral frequency versus time for the same trace reveals stable high-frequency activity.

$37^{\circ} \mathrm{C} / 5 \% \mathrm{CO}_{2}$ incubator and analyzed for electrophysiological activity every week for at least 4 weeks postinjection.

Organotypic hippocampal slices. Organotypic slices were prepared as described previously (Stoppini et al., 1991; Scheffler et al., 2003; Opitz et al., 2007). Briefly, 400- $\mu$ m-thick transverse hippocampal slices were cut from P6 male and female rats pups (Sprague Dawley, Harlan) in ice-cold calcium-free MEM. Immediately after sectioning, the slices were transferred on Millicell-CM membrane inserts (Millipore) in wells containing culture medium of the following composition: 50\% Basal Medium Eagle, 25\% horse serum, 19\% Earle's balanced salt solution, 25 mM HEPES, 32 mM glucose; $2 \mathrm{~mm}$ glutamine, $100 \mu \mathrm{g} / \mathrm{ml}$ streptomycin, $2.5 \mu \mathrm{g} / \mathrm{ml} \mathrm{am}$ photericin $\mathrm{B}, \mathrm{pH} 7.20$. Slices were kept in a humidified incubator at $37^{\circ} \mathrm{C}$ in $5 \% \mathrm{CO}_{2}$. After $24 \mathrm{~h}$, slices were transferred to a maintenance culture medium of similar composition with a lower concentration of horse serum (5\%). Media was changed every 3-4 d.

Electrophysiology. For cultures, whole-cell recordings were performed at room temperature $\left(22^{\circ} \mathrm{C}\right)$ using a patch-clamp amplifier (Multiclamp 700B, Molecular Devices). Cells on coverslips were placed in a $150 \mu \mathrm{l}$ recording chamber mounted on the stage of an
Olympus IX71 inverted microscope. Cells were continuously superfused with HEPES-buffered external solution of the following composition (in mM): $137 \mathrm{NaCl}, 1 \mathrm{NaHCO}_{3}, 0.34 \mathrm{Na}_{2} \mathrm{HPO}_{4}, 2.5 \mathrm{KCl}, 0.44$ $\mathrm{KH}_{2} \mathrm{PO}_{4}, 2.5 \mathrm{CaCl}_{2}, 5$ HEPES, 22.2 glucose, $\mathrm{pH}$ adjusted to 7.3 with $\mathrm{NaOH}$. Patch pipettes were pulled from borosilicate glass capillaries (G150F-3, Warner Instruments) using a Flaming/Brown micropipette puller (P-97, Sutter Instruments). Patch pipettes had open tip resistances of 4-10 $\mathrm{M} \Omega$. For organotypic slices, extracellular field potentials were recorded at $35^{\circ} \mathrm{C}$ using a multielectrode array (MEA60, Multi Channel Systems). The MEA chamber contained 60 electrodes, each $30 \mu \mathrm{m}$ in diameter and placed $200 \mu \mathrm{m}$ apart. Slices were held down against the electrodes by a ring with a fine mesh and continuously superfused with bicarbonate-buffered artificial CSF composed of the following (in $\mathrm{mM}$ ): $125 \mathrm{NaCl}, 2.5 \mathrm{KCl}, 2 \mathrm{CaCl}_{2}, 1 \mathrm{MgCl}_{2}, 1.25 \mathrm{NaH}_{2} \mathrm{PO}_{4}, 25 \mathrm{NaHCO}_{3}, 10$ D-glucose, $\mathrm{pH}$ 7.4, osmolarity $310 \mathrm{mOsm}$. Photostimulation of optogenetic constructs was controlled via a xenon lamp in a Lambda DG-4 High Speed Filter Changer (Sutter Instruments) equipped with appropriate excitation filters (ChR2: FF01-475/35-25; NpHR: FF01-585/40-25, Semrock). 

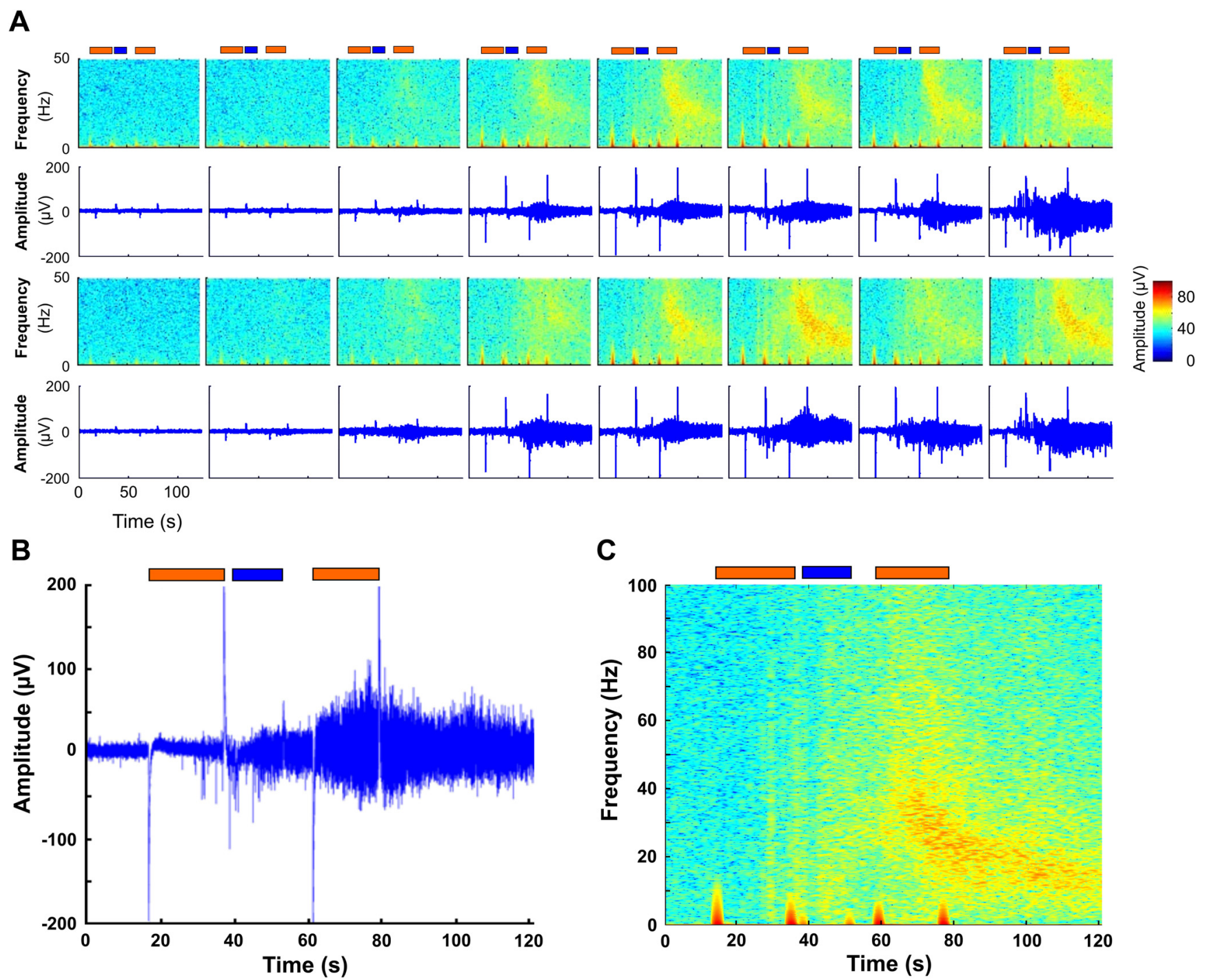

Figure 3. Power spectral analysis of extracellular field potentials generated during transient photostimulation of organotypic hippocampal slice transplanted with hESC-derived neurons. $\boldsymbol{A}$, Analysis of $125 \mathrm{~s}$ epoch of extracellular activity recorded simultaneously in 16 different electrodes during transient photostimulation. Graphic representation of frequency versus time reveals electrical activity elicited by application of light with peak wavelength $585 \mathrm{~nm}$ (orange boxes) and $475 \mathrm{~nm}$ (blue boxes). As shown in Fig. 1C, a pattern of photostimulation consisting of orange light $(585 \mathrm{~nm})$ to elicit hyperpolarization via NpHR, followed by blue light $(475 \mathrm{~nm})$ to elicit depolarization via ChR2, consistently evoked neuronal activity. The large upward and downward deflections in the baseline are the stimulus artifacts at the beginning and the end of each light pulse. $\boldsymbol{B}, \boldsymbol{C}$, Magnified panels from $\boldsymbol{A}$, show that photostimulation generated transient bursts of high-frequency activity that reached well into the gamma range $(100 \mathrm{~Hz})$. Once evoked, these oscillations outlasted the light stimulation and were unresponsive to subsequent illumination with hyperpolarizing orange light ( $585 \mathrm{~nm})$.

\section{Results}

\section{Generation of optogenetically competent} hESC-derived neurons

To confer the ability for optogenetic stimulation to our transplanted cells, neural progenitor cells (hESC-derived NPCs) were transduced with lentiviral expression vectors containing channelrhodopsin (pSynI-ChR2-EYFP) as an excitatory ion channel, and halorhodopsin (pEF1-NpHR-mCherry) as an inhibitory transporter (Fig. 1A) (Zhang et al., 2006). When assayed electrophysiologically, hESC-derived neurons displayed resting membrane potentials of $\sim-50 \mathrm{mV}$ and spontaneous action potentials that were sensitive to the selective sodium channel blocker tetrodotoxin $(1 \mu \mathrm{M}$; Fig. $1 B)$. Next, we recorded from these hESC-derived neurons with a patch electrode in voltage-clamp mode to obtain evidence for the expression of the optogenetic constructs by observing both depolarizing and hyperpolarizing light-activated responses
(Fig. $1 C, n=4$ cells). The hESC-derived NPCs had differentiated to the neuronal phenotype as evidenced by electrophysiological criteria, including firing action potentials (Fig. 1B) and immunocytochemical evidence based on multiple markers (Fig. 1D) (Li et al., 2008; Cho et al., 2011).

MEF2CA-driven neuronal differentiation (Li et al., 2008; Cho et al., 2011) produced neurons with typical neuronal phenotype, as seen with immunocytochemical staining for the specific neuronal markers synapsin 1 and MAP2, synaptophysin, tau protein (Fig. 1D), and TuJ1 (Fig. 1E). When MEF2CA-programmed (compared with vector-infected control) hESC-derived neurons were analyzed for the presence of neurotransmitter specific markers, they showed high levels of expression of the synthetic enzymes tyrosine hydroxylase and glutamic acid decarboxylase (Fig. 1E), indicating an abundance of dopaminergic and GABAergic neurons, respectively. At the same time, hESC-derived neurons manifested relatively low levels of vesicular glutamate 
transporter 1 protein, indicating generation of a lower number of glutamatergic neurons than under control conditions (Fig. 1E).

\section{High-frequency oscillations after functional integration of optogenetically competent hESC-derived neurons}

To study the integration of hESC-derived NPCs into CNS tissue, we transplanted these cells, after viral infection, onto hippocampal slices and cultured them for up to 7 weeks at $37^{\circ} \mathrm{C}$ and $5 \% \mathrm{CO}_{2}$. Slices were assayed using pulses of light at wavelengths of 475 and $585 \mathrm{~nm}$ to activate ChR2 and NHpR2, respectively. Starting 2 weeks posttransplantation, cells with characteristic neuronal morphology and long processes that extended for hundreds of micrometers could be seen on the slices (Fig. 1F). Control slices without transplanted hESCderived neurons or with transplanted hESC-derived neurons expressing GFP only (without optogenetic constructs) did not respond to light stimulation (Fig. $1 G$ ). In contrast, photostimulation of slices transplanted with hESC-derived neurons expressing optogenetic constructs elicited oscillations several millimeters distal to the site of the transplanted cells, whose location could be monitored by the presence of fluorescent markers (Fig. 2A,B). This network activity was characterized by a transient initial phase of high-frequency oscillations in the $\gamma$-band range followed by persistent lower frequency oscillations in the $\beta$ range (Figs. $2 C-F, 3 ; n=18$ slices analyzed). The low frequency of spikes associated with these oscillations suggested that this network phenomenon did not represent seizure activity (Khazipov and Holmes, 2003). Thus, the transplanted hESC-derived NPCs developed into neurons capable of driving an endogenous neuronal network in the hippocampus at some distance from the site of transplantation.

\section{Discussion}

This study supports the use of slice preparations (Scheffler et al., 2003; Opitz et al., 2007) with optogenetic technology (Zhang et al., 2006), not only to assess single cell activity as previously reported (Weick et al., 2010, 2011), but also to monitor network events associated with the functional integration of engrafted stem cell-derived neuronal populations into CNS tissue. Importantly, this is the first demonstration that a population of transplanted stem cell-derived neurons can integrate into and participate in endogenous neuronal network activity. We show that MEF2CA-driven neuronal differentiation produces a neuronal population enriched in dopaminergic and GABAergic neurons, which are known to play a role in the generation and modulation of high-frequency oscillations in the hippocampus (Mann and Paulsen, 2007; Andersson et al., 2012). Hence, the light-induced highfrequency oscillations that we observed in organotypic slices may be explained at least in part by the ability of the newly formed, optogenetically competent hESC-derived GABAergic and dopaminergic neurons to synchronize local neuronal networks within the hippocampus. The need for relatively long $(10-20 \mathrm{~s})$ periods of light stimulation for the induction of oscillations may relate to the relatively immature state of the hESC-derived neurons at the time of the experiments, as shown by their somewhat depolarized resting membrane potential. An interesting network behavior that we observed during optogenetic stimulation of engrafted hESC-derived neurons was a shift from gamma to slower beta oscillations, which has been previously described in human brain EEGs during sensory stimulation (Haenschel et al., 2000) and in acute hippocampal slices during electrical stimulation (Traub et al., 1999b). Because fast neuronal oscillations in the $\beta / \gamma$ range $(10-100 \mathrm{~Hz})$ are linked to the performance of sensorymotor and cognitive tasks (Gray, 1994; Wang, 2010) and disruption of such network activity has been shown to accompany neuronal dysfunction in neurological disorders (Uhlhaas and Singer, 2006; Barth and Mody, 2011), transplantation of optogenetically controllable hESC-derived NPCs can potentially be used to restore neuronal network activity, and thus reestablish motor and cognitive function (Traub et al., 1999a; De Feo et al., 2012). Similarly, the use of combined optogenetic and MEA techniques should prove useful in the assessment of functional integration of transplanted stem cellderived neurons in a variety of in vivo paradigms.

\section{References}

Andersson RH, Johnston A, Herman PA, Winzer-Serhan UH, Karavanova I, Vullhorst D, Fisahn A, Buonanno A (2012) Neuregulin and dopamine modulation of hippocampal gamma oscillations is dependent on dopamine D4 receptors. Proc Natl Acad Sci U S A 109:13118-13123.

Barth AM, Mody I (2011) Changes in hippocampal neuronal activity during and after unilateral selective hippocampal ischemia in vivo. J Neurosci 31:851-860.

Benninger F, Beck H, Wernig M, Tucker KL, Brüstle O, Scheffler B (2003) Functional integration of embryonic stem cell-derived neurons in hippocampal slice cultures. J Neurosci 23:7075-7083.

Cho EG, Zaremba JD, McKercher SR, Talantova M, Tu S, Masliah E, Chan SF, Nakanishi N, Terskikh A, Lipton SA (2011) MEF2C enhances dopaminergic neuron differentiation of human embryonic stem cells in a Parkinsonian rat model. PLoS One 6:e24027.

De Feo D, Merlini A, Laterza C, Martino G (2012) Neural stem cell transplantation in central nervous system disorders: from cell replacement to neuroprotection. Curr Opin Neurol 25:322-333.

Elkabetz Y, Studer L (2008) Human ESC-derived neural rosettes and neural stem cell progression. Cold Spring Harb Symp Quant Biol 73:377-387.

Fischer Y, Wittner L, Freund TF, Gähwiler BH (2002) Simultaneous activation of gamma and theta network oscillations in rat hippocampal slice cultures. J Physiol 539:857-868.

Gray CM (1994) Synchronous oscillations in neuronal systems: mechanisms and functions. J Comp Neurosci 1:11-38.

Haenschel C, Baldeweg T, Croft RJ, Whittington M, Gruzelier J (2000) Gamma and beta frequency oscillations in response to novel auditory stimuli: a comparison of human electroencephalogram (EEG) data with in vitro models. Proc Natl Acad Sci U S A 97:7645-7650.

Khazipov R, Holmes GL (2003) Synchronization of kainate-induced epileptic activity via GABAergic inhibition in the superfused rat hippocampus in vivo. J Neurosci 23:5337-5341.

Kim JH, Auerbach JM, Rodríguez-Gómez JA, Velasco I, Gavin D, Lumelsky $\mathrm{N}$, Lee SH, Nguyen J, Sánchez-Pernaute R, Bankiewicz K, McKay R (2002) Dopamine neurons derived from embryonic stem cells function in an animal model of Parkinson's disease. Nature 418:50-56.

Lee JP, Jeyakumar M, Gonzalez R, Takahashi H, Lee PJ, Baek RC, Clark D, Rose H, Fu G, Clarke J, McKercher S, Meerloo J, Muller FJ, Park KI, Butters TD, Dwek RA, Schwartz P, Tong G, Wenger D, Lipton SA, et al. (2007) Stem cells act through multiple mechanisms to benefit mice with neurodegenerative metabolic disease. Nat Med 13:439-447.

Li Z, McKercher SR, Cui J, Nie Z, Soussou W, Roberts AJ, Sallmen T, Lipton JH, Talantova M, Okamoto S, Lipton SA (2008) Myocyte enhancer factor $2 \mathrm{C}$ as a neurogenic and antiapoptotic transcription factor in murine embryonic stem cells. J Neurosci 28:6557-6568.

Mann EO, Paulsen O (2007) Role of GABAergic inhibition in hippocampal network oscillations. Trends Neurosci 30:343-349.

Opitz T, Scheffler B, Steinfarz B, Schmandt T, Brüstle O (2007) Electrophysiological evaluation of engrafted stem cell-derived neurons. Nat Protoc 2:1603-1613.

Scheffler B, Schmandt T, Schroder W, Steinfarz B, Husseini L, Wellmer J, Seifert G, Karram K, Beck H, Blümcke I, Wiestler OD, Steinhäuser C, Brüstle O (2003) Functional network integration of embryonic stem cell-derived astrocytes in hippocampal slice cultures. Development 130: 5533-5541. 
Stoppini L, Buchs PA, Muller D (1991) A simple method for organotypic cultures of nervous tissue. J Neurosci Methods 37:173-182.

Taketani M, Baudry M (2006) Advances in network electrophysiology: using multi-electrode arrays. New York: Springer.

Traub RD, Jefferys JGR, Whittington MA (1999a) Fast oscillations in cortical circuits. Cambridge: MIT.

Traub RD, Whittington MA, Buhl EH, Jefferys JG, Faulkner HJ (1999b) On the mechanism of the gamma $\rightarrow$ beta frequency shift in neuronal oscillations induced in rat hippocampal slices by tetanic stimulation. J Neurosci 19:1088-1105.

Uhlhaas PJ, Singer W (2006) Neural synchrony in brain disorders: relevance for cognitive dysfunctions and pathophysiology. Neuron $52: 155-168$.
Wang XJ (2010) Neurophysiological and computational principles of cortical rhythms in cognition. Physiol Rev 90:1195-1268.

Weick JP, Johnson MA, Skroch SP, Williams JC, Deisseroth K, Zhang SC (2010) Functional control of transplantable human ESC-derived neurons via optogenetic targeting. Stem Cells 28:2008-2016.

Weick JP, Liu Y, Zhang SC (2011) Human embryonic stem cell-derived neurons adopt and regulate the activity of an established neural network. Proc Natl Acad Sci U S A 108:20189-20194.

Wernig M, Benninger F, Schmandt T, Rade M, Tucker KL, Büssow H, Beck H, Brüstle O (2004) Functional integration of embryonic stem cell-derived neurons in vivo. J Neurosci 24:5258-5268.

Zhang F, Wang LP, Boyden ES, Deisseroth K (2006) Channelrhodopsin-2 and optical control of excitable cells. Nat Methods 3:785-792. 